\title{
La derecha peruana de encomenderos a neoliberales, pero siempre encomenderos ${ }^{*}$
}

Recibido: $18 / 05 / 2020$

Aprobado: 30/08/2020
NICOLÁS LYNCH

Universidad Nacional Mayor de San Marcos

nlynchg@unmsm.edu.pe

https://orcid.org/0000-0001-7205-7602

\section{RESUMEN}

Este artículo plantea el origen y desarrollo de la derecha peruana como una derecha neoliberal en el período 1990-2020. El argumento busca las raíces de esta expresión política en la historia peruana y en la comparación con derechas anteriores. En el período de estudio y en un primer momento con el fujimorismo, esta es una derecha autoritaria. En uno segundo, una derecha que mantiene la continuidad del modelo, pero transita a la democracia. Se trata, sin embargo, de una transición inacabada porque la continuidad neoliberal promueve una democracia limitada, representada por políticos, pero administrada por tecnócratas y vigilada por los grandes propietarios. Los escándalos de corrupción de los últimos años revelan el agotamiento de este arreglo y por falta de una alternativa, la salida hoy se juega entre dos facciones del neoliberalismo, los restos y herederos del fujimorismo y la procreada en democracia, que no son capaces todavía de definir la situación y esto podría incluir a un tercer actor.

Palabras clave: Derecha; neoliberalismo; tecnócratas; captura; Perú.

\section{From encomenderos to neoliberals that remain encomenderos in the Peruvian Right}

\begin{abstract}
This article places the origin and development of the Peruvian Right as a neoliberal right over the period 1990-2020. The study delves into the roots of this political notion in Peruvian history, and compares it to previous rights. At the beginning of the examined period, during Fujimorism, it is an authoritarian right. Subsequently, it becomes a right that ensures the continuity of the model while it transitions to democracy. However, it is an unfinished transition as the neoliberal continuity promotes a limited democracy, represented by politicians but run by technocrats, and policed by large business owners. Corruption scandals in recent years have revealed the exhaustion of this arrangement, and in the absence of an alternative two factions of neoliberalism compete for finding a way out, the remains and heirs to Fujimorism, and the one born in democracy. Neither has yet proven able to define the situation, which could make room for a third actor.
\end{abstract}

Keywords: Right; neoliberalism; technocrats; capture; Peru.

\footnotetext{
* Una versión preliminar de esta investigación fue publicada en CIDOB d’Afers Internacionals $\mathrm{N}^{\circ} 126$, año 2020.
} 


\section{Introducción}

|| ablar de derecha nos lleva a tratar el enojoso tema de la definición. Más allá de un recorrido heurístico prefiero la muy conocida de Norberto Bobbio (1996) que define la derecha en contraposición a su tradicional opuesto la izquierda. Nos dice Bobbio que lo distintivo de la tradicional oposición es que la derecha considera la desigualdad una cuestión natural y la izquierda una construcción social, por lo que la primera no promueve la superación de la desigualdad, mientras que la segunda señala que esta superación es un objetivo fundamental de su acción.

Esta cuestión adquiere la mayor relevancia en el caso peruano, una realidad histórica y agudamente desigual, porque el orden político posterior a la independencia de España ha naturalizado la desigualdad convirtiendo en moneda corriente que un pequeño grupo viva a costa de los demás (Alarco, Castillo y Leiva 2019) (Latinobarómetro 2018). ${ }^{1}$ Quizás quien mejor recoja esta situación sea el historiador Mark Thurner (2006) cuando señala que lo que hoy es el Perú pasó de las dos repúblicas en la colonia, la república de indios y la república de españoles, a una república dividida en dos, con - agrego- el grupo de raíz colonial dominando a los demás.

No es gratuita por ello la comparación de los neoliberales acutales con los encomenderos de la época colonial. Al encomendero en la colonia temprana se le asignaba un número de indios del cual se le hacía reponsable, se supone que en su sustento y adoctrinamiento en la religión católica. En la práctica el encomendero los hacía trabajar sin velar por su sustento, lo que en términos modernos llamaríamos por la reproducción de su fuerza de trabajo. Esta sobrexplotación fue una de las causas de la hecatombe demográfica del siglo XVI, en especial por la denominada "mita minera", en el territorio de lo que en ese entonces se llamaba el virreinato del Perú, hecatombe que redujo según Watchel (1976) y Araníbar (1979) en un 90 \% la población aborigen. Guardando las distancias, se reproduce en la actualidad una relación entre capital y trabajo que tiene su cordón umbilical con el pasado encomendero. Me refiero a la sobrexplotación de la fuerza de trabajo local, tanto del reducido empleo formal existente, como de la articulación entre formalidad e

$1 \quad$ El análisis que hacen de las distintas correcciones al coeficiente de Gini del ingreso Alarco, Castillo y Leiva (2019) sitúa a la medida de desigualdad muy por encima del índice de Gini oficial que mide el Instituto Nacional de Estadística e Informática (INEI) y el censo en estos últimos años. Como ejemplo podemos señalar que el índice oficial se sitúa alrededor del 0.45 , mientras que los corregidos alcanzan hasta 0.7 , una medida pavorosa de la desigualdad en el Perú. 
informalidad laboral, al no estar interesada la clase propietaria en el pago de buenos salarios porque no realizan lo principal de sus ganancias en el mercado interno peruano sino en la exportación de materias primas, curiosamente también minerales, para el mercado mundial (Marini 1973). Se da aquí una sobrexplotación que combina desprecio étnico y de clase, al no considerar en igual condición de humanidad a patrones, pertenecientes a un ancestro europeo, que a trabajadores, mayoritariamente de ancestro indígena. La herencia colonial se encuentre así trágicamente presente.

En línea con lo anterior, y a diferencia de otros textos sobre el mismo tema (Vergara 2012, Meléndez 2019), asumo una posición normativa tratando de entender la derecha en el contexto mayor de la formación social peruana y de su manifestación última y actual como derecha neoliberal. Para ello caracterizo el período actual de dominio neoliberal en dictadura y luego en democracia, analizo las coyunturas importantes de origen en la década de 1990, de transición frustrada en los 2000 y la crisis irresuelta en la actualidad. Hago esto con intención de ver las posibilidades de desenlace que se pueden dar en el corto/mediano plazo.

Si algo distingue a la derecha peruana del resto de América Latina es que ha gobernado el país sin interrupciones desde 1990. Esto significa que ha establecido una hegemonía política e ideológica en los últimos 30 años que le da la capacidad para tener vigencia hasta el día de hoy. No lo ha hecho como antaño con una invocación general a su carácter de élite que, por diversas razones, de propiedad y/o intelecto, tendría el derecho a mandar, sino con un programa muy claro de reorganización de la sociedad y el Estado, en contraste con la realidad anterior de crisis que buscaba dejar atrás. Me refiero a la aplicación de lo que se ha venido en llamar el modelo neoliberal del Consenso de Washington o el establecimiento de la lógica del mercado para el funcionamiento del país.

Esta hegemonía es la que le permite mantenerse en el poder a través de sucesivas crisis en estas tres décadas y en especial luego del desgobierno de los últimos tres años. En este último período ha renunciado un presidente, todos los demás están investigados o presos por corrupción e incluso uno de ellos se suicidó cuando los fiscales llamaron a su puerta para detenerlo. Además, el Parlamento elegido en el 2016 para un período de cinco años fue disuelto en octubre del 2019 por reiterada actitud obstruccionista con el Poder Ejecutivo. A consecuencia de ello tuvimos elecciones parlamentarias extraordinarias para elegir un Parlamento que cubriera el período que faltaba al ante- 
rior hasta julio del 2021 y ganaron listas sin aparente relación con los partidos que generaron la crisis, pero tampoco ninguna alternativa hacia adelante. Esta situación parece abrir una crisis de régimen, aunque sin solución a la vista.

En estas condiciones: ¿qué es permanente y qué nuevo en la derecha peruana? Creo que lo permanente es su carácter oligárquico, colonial, racista y patrimonial y lo nuevo es haber asumido un modelo capitalista, ligado a la globalización neoliberal, que ha proyectado las ventajas del patrimonialismo hasta límites desconocidos en nuestra historia, dándole una capacidad hegemónica poco común en las derechas de la región.

\section{Origen de la nueva derecha}

Como bien nos recuerda Carlos Alberto Adrianzén (2014), la derecha neoliberal en el Perú tiene su primera expresión ideológica en la prédica de dos intelectuales: Felipe Ortiz de Zevallos, cabeza del grupo empresarial Apoyo, y Hernando de Soto, autor del libro El otro sendero (1986). Sin embargo, quien la lleva a la acción política es el escritor Mario Vargas Llosa y su movimiento Libertad en la campaña que desarrolla entre 1985 y 1990 (Adrianzén 2014). Aunque su plasmación como una política pública recién se da con el ajuste económico de principios de agosto de 1990, que aplica el gobierno recién electo de Alberto Fujimori, haciendo cuando llega al gobierno exactamente lo contrario de lo que dijo que iba a hacer cuando estuvo en campaña. Esto se da en un clima de época en el mundo, que tiene sus referencias mayores en Margaret Thatcher y Ronald Reagan y que había tenido adelantados en América Latina, con las dictaduras militares de Augusto Pinochet y Jorge Videla, así como seguidores civiles, como son los gobiernos de la concertación en Chile, Carlos Menem en Argentina y la vuelta de tuerca del régimen priísta con Carlos Salinas en México.

Sin embargo, esta derecha, en su versión fujimorista, afirma su poder casi dos años más tarde, con el autogolpe del 5 de abril de 1992, cuando Alberto Fujimori y su asesor de inteligencia Vladimiro Montesinos, dan un viraje autoritario y establecen una dictadura, que dura hasta la huida del Perú de Fujimori y su posterior destitución en noviembre del año 2000. El ajuste económico y luego el golpe tienen su corolario en una nueva Constitución, elaborada por un Congreso elegido en dictadura y ratificada por un referéndum fraudulento en octubre de 1993 (Chávez Molina, 2000). La Constitución, promulgada en 
estas condiciones, con su restricción de derechos, concentración del poder y capítulo económico, ha sido la base para las reformas neoliberales.

Este inicio autoritario es clave porque va a dar la pauta - ajuste, golpe y nueva Constitución - primero en dictadura y luego en democracia, de los treinta años que hemos vivido bajo el modelo neoliberal.

Ahora bien, este origen es a la vez una ruptura con el período anterior (1962-1990) que de manera genérica podemos llamar reformista en la política peruana y a la vez una reconversión de la derecha histórica anterior a 1968. Si tomamos como referencia la relación sociedad-Estado y seguimos las reflexiones de Francisco Durand (2019), tenemos que en el período reformista el gran intento transformador es separar a las clases propietarias del Estado para tener, aunque fuera hipotéticamente, un Estado al servicio de todos, un Estado que en el siglo XX se considera moderno (Weber 1982). Mientras que de 1990 en adelante se procede a la captura o mejor dicho a la recaptura del Estado por las clases propietarias. El gran pretexto de este cambio es el fracaso del período reformista por conseguir hacer perdurables las reformas llevadas adelante que se plasman en el intento de separación antedicho. En su extremo, este fracaso es patente en la violencia política y su secuela terrorista, así como en la hiperinflación de la época, ambos fenómenos que suceden principalmente en la segunda mitad de la década de 1980. Este fracaso del reformismo es lo que le da una legitimidad de origen a la derecha neoliberal para su recaptura.

El período reformista, sin embargo, es el epílogo de un largo proceso de dominación oligárquica que se va erosionando desde 1930, pero que termina con el golpe militar del tres de octubre de 1968 que da inicio al gobierno nacionalista del general Juan Velasco Alvarado (Pease 1978, Franco 1985). La dominación oligárquica es una alianza de clases, definida por Sinesio López (1991) como la articulación terrateniente de la oligarquía costeña dedicada a la agroexportación y el gamonalismo andino basado en la servidumbre, ligados como alianza social y política al capital extranjero que estaba presente a través de enclaves mineros y agrícolas. La derecha histórica se establece así como oligarquía terrateniente en el siglo XIX, heredera de la dominación colonial española, como explotación social y opresión racial de una pequeña minoría de ancestro europeo sobre la inmensa mayoría de los peruanos, principalmente campesina e indígena.

El establecimiento de la derecha histórica como una élite heredera de la colonia es fundamental para entender a la derecha en el Perú. Aníbal Quijano 
(2000) nos dirá en su texto sobre la colonialidad del poder que la dependencia peruana, colonial primero y neocolonial después, tiene dos aspectos: la dependencia externa del país respecto de un centro de poder mundial y el colonialismo interno (González Casanova 1963, 2003), que organiza las jerarquías sociales a través de una clasificación racial. El colonialismo interno como característica constitutiva se expresa entonces en la diferenciación racial y finalmente en el racismo como norma de interacción social.

Oligarquía, colonialismo y racismo llevan a una cuarta característica constitutiva de la derecha peruana: el patrimonialismo o la no distinción entre el bolsillo privado y el tesoro público. Julio Cotler (1978) señalaba que el patrimonialismo viene directamente del régimen colonial, en el que el rey de España consideraba al virreinato del Perú su patrimonio personal y concedía a sus súbditos la gracia de administrarlo. Esa característica se va a transmitir al grupo criollo que hereda a la administración colonial en la república peruana temprana. Alfonso Quiroz (2013) en su Historia de la corrupción en el Perú, va a señalar la importancia del asalto a los fondos públicos en la conformación de las grandes fortunas desde un momento tan temprano como la década de 1840, cuando se produce la estafa de los bonos de la deuda interna o el reclamo falso de haberle prestado dinero y/o bienes al ejército patriota en la guerra de Independencia. Me parece muy importante señalar el origen estructural de la corrupción en el patrimonialismo, como característica fundante de la república criolla. De allí, su repetición endémica en la conducta del grupo dominante hasta el día de hoy, en el que la corrupción se convierte en el azote de la democracia y en la distinción de su precariedad.

He señalado las grandes características comunes a la derecha en el Perú y creo que tanto la derecha que funda la república criolla (Lynch 2014) y que podríamos llamar la vieja oligarquía, como la derecha neoliberal que surge del ajuste, el golpe y la Constitución de 1993, comparten oligarquía, colonialidad, racismo y patrimonialismo.

Empero, ¿qué distingue a la vieja oligarquía de la derecha neoliberal? El carácter abiertamente delictivo de la conducta política de esta última, sin legitimidad tradicional que la sustente. La vieja oligarquía todavía gozaba del imperio de la costumbre que permitía al señor considerar las arcas públicas como su botín, esto se va diluyendo con la crisis del Estado oligárquico y termina con las reformas velasquistas de la década de 1970. En el caso de la derecha neoliberal, esta característica corrupta estuvo reservada por los estudiosos al fujimorismo, por el carácter mafioso de su actuar y la mega 
corrupción resultante en la década de 1990; pero luego con los escándalos de corrupción que han salido y continúan saliendo a la luz en los últimos años, podemos señalar que se trata de un fenómeno sistémico y transversal de la época neoliberal, por supuesto sin legitimidad que lo ampare.

Esta falta de legitimidad se hace patente con la crisis, que como veremos más adelante alcanza su punto más alto como crisis de régimen y cuestiona en su gravedad a este tipo de capitalismo neoliberal para ser una vía de desarrollo exitosa para el Perú. Si fuera un capitalismo con posibilidades, en sus propios términos me refiero, generaría algún tipo de legitimidad, legal especialmente, pero sucede que si algo se viola constantemente en el Perú en estos años es la ley, generando como diría Carlos Franco (1985) particularismo y no universalismo en el proceso de dominación.

Asimismo, cabe también señalar si comparamos vieja oligarquía con la derecha neoliberal actual, que ambas se establecen luego de sendos conflictos bélicos. ${ }^{2}$ La vieja oligarquía después de la guerra con Chile, administrando la derrota de manera tal que centralizan el poder político sin borrar el estigma colonial y afianzan el modelo exportador de materias primas y la dependencia, de Inglaterra primero y luego de los Estados Unidos. Sin embargo, en este proceso, crean su contrario, las fuerzas nacionales y populares, el APRA, el Partido Comunista y los epígonos de ambos, que terminan con sus posibilidades políticas con la crisis de 1930 e históricas con las reformas velasquistas de 1968 en adelante. La derecha neoliberal, por su parte, surge de la derrota de Sendero Luminoso y el Movimiento Revolucionario Túpac Amaru, en lo que se ha venido en llamar el "conflicto armado interno" (Comisión de la Verdad 2004). Esta derrota la consigue el Estado peruano por la vía de la guerra sucia, es decir a un alto costo en términos de derechos humanos, en especial para la población campesina, indígena y quechuahablante, a la que pertenecen la mayor parte de los 69000 muertos. En ambos casos la consecuencia de la guerra es el fortalecimiento y mejor organización de la dominación, aunque por el carácter excluyente de sus proyectos no puedan superar el tiempo medio de los 30-40 años sin llegar a la crisis y eventualmente generar su contrario. La derecha neoliberal, sin embargo, es más cosmopolita y se proyecta a un mundo circundante que la favorece durante un buen tiempo. Asimismo, logra hegemonizar a importantes sectores populares, más allá de la dialéctica amoesclavo, propia de la vieja oligarquía, es decir más allá de la creencia, propia

2 Agradezco el comentario de César Aguilar en este punto. 
de la tradición, que los señores y/o patrones tienen el derecho natural a mandar. Lo hace victoriosa, de allí, como veremos más adelante, su capacidad de "terruquear", ${ }^{3}$ es decir de llamar terrorista a cualquiera que reclame derechos ciudadanos.

\section{La derecha neoliberal como fujimorismo}

A la recaptura a la que hago referencia la he denominado también (Lynch 2009), para explicar su momento fundacional, regresión autoritaria, en contraste con lo que había significado la transición a la democracia de fines de la década de 1970 y los gobiernos reformistas tanto civiles como militares de las décadas de 1960 y 1970.

En este sentido, un dato muy importante para el establecimiento de la derecha neoliberal es el inicio autoritario. Si bien el período comienza con el triunfo electoral de Alberto Fujimori en julio de 1990, rápidamente se da un viraje autoritario con el ajuste de 1990 y el golpe de abril de 1992. Esto último, justamente porque el Congreso de entonces rechaza la aprobación de un paquete de decretos legislativos ${ }^{4}$ para la lucha antiterrorista que restringía los derechos de la ciudadanía. A partir del golpe se instituye una dictadura ${ }^{5}$ que se basa en una alianza abierta de las Fuerzas Armadas, los grandes empresarios nacionales y extranjeros, y los organismos financieros internacionales; con el apoyo, reticente a veces, pero apoyo, al fin y al cabo, del gobierno de los Estados Unidos, por ello en la época se denomina al régimen como cívicomilitar. En estos primeros años se agrega a esta alianza el sector conservador de la Iglesia católica, cuando Juan Luis Cipriani, miembro del Opus Dei, asume como arzobispo de Lima y es hecho cardenal por Juan Pablo II (Adrianzén 2014).

3 Terruquear es una palabra que surge por el reiterado afán de la derecha neoliberal de levantar el tema del terrorismo, como una manera de asustar a la población cada vez que hay una movilización social que reclama derechos conculcados a algún sector de la población. Viene de "terruco", derivada a su vez de terrorista, que era como se llamaba a los integrantes de Sendero Luminoso que se caracterizó por sus múltiples atentados terroristas en la época del conflicto armado interno.

4 Legislación de emergencia dada directamente por el Poder Ejecutivo en el Perú.

5 Hay, sin embargo, quien cuestiona esta caracterización de dictadura. Martín Tanaka (2005) señala más bien que se trataría de un autoritarismo competitivo, debido a que hay elecciones y se pone nuevamente a funcionar, aunque bajo control del gobierno, el Congreso y el Poder Judicial. Creo que Tanaka se equivoca al considerar que, al no haberse cerrado todos los espacios de contestación política, no se trata de una dictadura. Se confunden aquí las formalidades con el fondo de las cosas, privilegiando el funcionamiento institucional a los fraudes, las trampas, la imposibilidad del control y la represión abierta y reiterada. Se relativiza así el autoritarismo del régimen y el daño en la futura democracia. 
Aquí es muy importante señalar que el liderazgo de esta alianza, constituido por Alberto Fujimori y Vladimiro Montesinos, le da un giro mafioso a la situación convirtiendo al Estado en una maquinaria delincuencial a su servicio, ${ }^{6}$ violando derechos humanos, asaltando fondos públicos, repartiendo prebendas a sus amigos, atacando cotidianamente la libertad de expresión, naturalizando el fraude electoral, amedrentando a sus enemigos e incluso eliminándolos, tal como se vería en sucesivas comisiones investigadoras del Congreso de la República del año 2000 en adelante. Esto lo reseñarían diversos autores (Rospigliosi 2000, Dammert 2001, Pease 2003) y se detallaría en la sentencia contra Alberto Fujimori de la Corte Suprema del Perú por hurto de fondos públicos y homicidio calificado el año 2009.

Sin embargo, hay que tomar en cuenta que la relación con el régimen de Fujimori y Montesinos es diferente para grandes empresarios y tecnócratas. Varios de los grandes empresarios, tanto nacionales como extranjeros, pasan a tener una relación directa con la cúpula del régimen, participando en negociados corruptos, así como en la negociación de grandes contratos de obra pública y de explotación de recursos naturales ${ }^{7}$ Los tecnócratas, por su parte, sin dejar de tener relación con los grandes empresarios y sus negocios corruptos, se apropian de la conducción del Ministerio de Economía y Finanzas, desde donde se proyectarán paso a paso en los años siguientes a los demás ministerios, primeros los ministerios productivos y luego los sociales. Esta nueva relación entre economía y política establecida por la derecha neoliberal es lo que Francisco Durand (2010) denomina captura del Estado y que por mi parte he calificado de "capitalismo de amigotes", un sistema en el que la rentabilidad de un negocio no estaba definida por la competitividad de los factores de producción sino por las buenas relaciones con las esferas del poder (Lynch 2009).

Lo interesante es que un componente clave de esta alianza de poder, los grandes empresarios y los organismos financieros internacionales, no parecen hacerse mayor problema con el carácter mafioso del régimen. Esto se

6 El uso del término "mafioso", tal como lo definen Dammert (2001) y Pease (2013), tiene que ver con la organización de un poder paralelo y oscuro, que no solo se refiere al control total de las instituciones, sino al uso del chantaje, el soborno y la amenaza cotidianas. En la organización y operación de este sistema, estuvieron, además de diversos organismos sectoriales del Estado con los que se estuviera tratando determinado problema, el Servicio de Inteligencia Nacional, articulado con los servicios de inteligencia de las Fuerzas Armadas y la Policía Nacional, a cargo de lo cual estaba Vladimiro Montesinos.

7 Manuel Dammert (2001), señala que solo en el caso de la privatización de las empresas públicas entraron al erario 6444 millones de dólares, encontrándose por el gobierno de transición de Valentín Paniagua, a fines del 2000, sin una cuenta clara de por medio, tan solo la cantidad de 543 millones de dólares. 
refleja en que la Confederación de Empresarios Privados (CONFIEP) no hiciera público ningún comunicado autocrítico luego de la caída de Fujimori y Montesinos, como sí lo hizo el Comando Conjunto de las Fuerzas Armadas el 5 de abril del $2001{ }^{8}$

Fue decisivo también el apoyo de una coalición internacional de fuerzas que poco a poco fue constituyendo esta derecha neoliberal. Tanto el ajuste como el golpe y luego la Constitución fueron claves para los grandes empresarios y los organismos financieros internacionales. Quizás quien mejor resuma este apoyo fue Michel Camdessus, en la época director ejecutivo del FMI, quien dijo cuando Fujimori fue a Washington en junio de 1990 a comunicar el viraje neoliberal, que estaba escuchando "música celestial". Sin embargo, en el caso de los gobiernos el asunto fue más complicado. La reacción inicial de Estados Unidos fue de condena y recién aceptó la situación cuando se regularizó, de acuerdo a sus estándares, el ciclo electoral a fines de 1992 (Cotler 2000). No le importó, al igual que a otros países latinoamericanos y europeos, los constantes cambios de reglas y las denuncias de fraudes posteriores. A lo sumo se limitaron, en algunas oportunidades, a acompañar las denuncias de violación a los derechos humanos que hicieran organismos especializados.

La contraparte de este poder autoritario y mafioso es el clientelismo político. Fujimori y especialmente Montesinos desarrollan una estrategia de clientelización de la población, enfocándose en los micro proyectos urgentes de comunidades urbanas y rurales, especialmente en pobreza y extrema pobreza. Toman como referencia para ello los resultados electorales obtenidos en distintos momentos y desarrollan como propósito el fidelizar una base social permanente que les dé su apoyo político. Este esfuerzo clientelista es llevado adelante por el Fondo de Cooperación para el Desarrollo Social (FONCODES) y tiene su inicio en el período 1993-1995, con singular éxito en el momento y proyección en el siglo XXI. ${ }^{9}$

También tenemos la obsesión legalista del régimen, en particular de Vladimiro Montesinos, pero no por el afán de cumplir la ley o de establecer nuevas reglas que deban ser cumplidas en este nuevo período, sino de cambiar

8 Ese día se publicó en los diarios de circulación nacional un comunicado de los militares donde hacían explícita su autocrítica del apoyo dado al régimen autoritario. Esto sucedió, de acuerdo con comunicación personal con el entonces asesor presidencial Alberto Adrianzén, por pedido expreso del presidente interino Valentín Paniagua.

9 Norbert Schady (1999) señala, en un texto de evaluación que escribe para el Banco Mundial, la relación entre el gasto efectuado, también con préstamos del propio Banco, y las simpatías políticas por el fujimorismo en la primera mitad de la década de 1990. 
la norma escrita cuantas veces sea necesario para adecuarla a las necesidades políticas del régimen autoritario, sin tener escrúpulos en los medios a utilizar para ese propósito, pero siempre teniendo un papel escrito y aprobado para referirse a él. ${ }^{10} \mathrm{Al}$ respecto, el régimen organizó un mega fraude en el referéndum de ratificación constitucional de octubre de 1993 por la necesidad que tenía de una nueva Constitución (Chávez Molina 2000). De igual forma, el Congreso sumiso al gobierno destituyó a los magistrados del Tribunal Constitucional que se negaron a aprobar la tercera reelección presidencial de Fujimori, lo que a la postre sería el detonante de los movimientos que años después derrocarían al régimen.

Pero junto con este tinglado político está el cambio en la hegemonía ideológica. El reformismo de la segunda mitad del siglo XX promueve un conjunto de sentidos anti oligárquicos, que tienen sus pilares en la justicia social, la soberanía y la identidad nacionales, la importancia de la organización popular y todos los derechos que ello conlleva, que amplían y multiplican la precaria ciudadanía anterior. A partir del ajuste económico, vía la terapia de schock (Klein 2006), se produce un esfuerzo del régimen orientado a borrar esta memoria de sentidos, identidades y derechos identificándola con el terrorismo de Sendero Luminoso. Es más, en los años posteriores al golpe del 5 de abril se persigue a todo aquel que reivindique estas banderas y establezca, aunque sea mínimamente, algún reclamo frente a la autoridad. Se sataniza de esta manera no solo identidades y derechos que se puedan relacionar con la izquierda, sino a la política y a los partidos en general. En contraparte, se desarrolla una campaña en varios frentes a favor de la iniciativa individual y la empresa privada. Esto tiene especial incidencia en los intentos de destrucción del trabajo con derechos que pasa a denominarse "sobre costo laboral" y en el elogio a la informalidad, que según Hernando de Soto sería el nuevo punto de partida para un empresariado popular y próspero.

Un rol especial en la construcción de la hegemonía neoliberal en este momento abiertamente autoritario lo tiene el control de los medios de comunicación. Junto con el golpe de Estado se desarrolla una política de amedrentamiento generalizada a los medios de comunicación masiva desarrollada a través de sucesivos operativos de inteligenica. Los que no se inclinan frente al poder son pocos, destaca el diario La República y en ocasiones el diario

10 "Papelito manda" era la expresión burlona que se acuñó en la época en referencia a los resultados electorales fraudulentos que pretendía hacer pasar por buenos un jefe del organismo electoral controlado por Montesinos. 
El Comercio, así como muy contados programas de radio y televisión. Pero quizás si la ofensiva más importante es la promoción de los llamados "diarios chichas", diarios populares de corte sensacionalista que se dedican a difamar a los enemigos del régimen y que son masivamente financiados por el gobierno de Fujimori y Montesinos. (Lynch 2002). Este control de los medios dificulta grandemente la acción opositora y juega a favor de la permanencia del régimen.

Asimismo, con la integración de monseñor Juan Luis Cipriani al núcleo de poder neoliberal en su versión fujimorista, también van a aparecer en el régimen autoritario los motivos del catolicismo conservador, especialmente en torno a la familia, el aborto y la educación. Esto será claro en la influencia que desarrollan en el Ministerio de Educación, en materias tales como la educación sexual y en la revisión general de los textos que el ministerio elaboraba para los estudiantes de la educación pública, que hacían funcionarios afines a esta visión conservadora. ${ }^{11}$

Este es el origen de la derecha neoliberal y, en particular, de su facción fujimorista. Se trata de una derecha que hereda de la oligarquía sus características de élite, coloniales, racistas y patrimoniales, pero agrega el autoritarismo mafioso y la burla reiterada de la ley, hasta de su propia ley, en el afán de ocultar su golpismo y aparecer legal en todo momento. Asimismo, es una derecha que se preocupa por establecer una base popular propia de carácter clientelista, por lo que mediáticamente, en especial sus medios afines, la han llamado "derecha popular". Esta característica, que es fundamental en los tiempos del gobierno de Fujimori, como base electoral y recurso de movilización en apoyo a sus políticas, va a permanecer como referencia entre los sectores populares y reaparecerá cuando el fujimorismo vuelva con fuerza a la escena política entre el 2010 y el 2019. El fujimorismo se convierte así en una marca de éxito electoral en la memoria de los sectores más pobres de la población en la década señalada.

Esta última caracterísitica de búsqueda de una base popular propia por parte del fujimorismo, a través del clientelismo, se ha tomado equivocadamente como ejemplo para establecer un concepto en la década de 1990. Este ha sido el caso del neopopulismo (Roberts 1995, Weyland 1997), que como

11 Me tocó como ministro de Educación del primer gabinete de un gobierno elegido luego del régimen autoritario desmontar el aparato que se había montado para este efecto de "lectura" de los materiales escolares. Asimismo, soportar la queja de monseñor Cipriani al presidente Toledo por tener un ministro de Educación que no era católico sino agnóstico. 
señalé en su momento (Lynch 1999) no es sino una pretensión de "estiramiento conceptual", recordando las reglas epistemológicas de Giovanni Sartori (1970), del concepto original populismo. Se confunde clientelismo con populismo, olvidando que este último en América Latina, más allá de sus deformaciones mediáticas, ha supuesto sobre todo un programa y un liderazgo de transformación social, de lo cual ciertamente estaba muy lejos el régimen de Alberto Fujimori y Vladimiro Montesinos.

\section{La derecha neoliberal como políticos, empresarios y tecnócratas}

El otro sector de la derecha neoliberal son los políticos, viejos y nuevos, y los grandes empresarios nacionales y extranjeros que empiezan a tener una influencia más directa y con una agenda propia sobre el poder. Esta presencia de los grandes empresarios se da junto con los tecnócratas neoliberales o más precisamente, como señala Jorge Domínguez (1998), los technopols, es decir los tecnócratas convertidos, o que buscan convertirse, en políticos.

Como vimos, hay un antecedente intelectual importante para el neoliberalismo peruano en Hernando de Soto y su libro El otro sendero (1986) en el que intenta, con una seriedad cuestionable, la posibilidad de un liberalismo popular. ${ }^{12}$ De Soto, más allá de la calidad de su propuesta, es avalado por grandes empresarios y tecnócratas que ven en él una forma de difundir el evangelio del libre mercado y a la postre el nuevo poder global que venían construyendo. Esta prédica adquiere importancia política con el surgimiento del movimiento Libertad de Mario Vargas Llosa, que se levanta contra la fallida expropiación de la banca en 1987. Es en este momento cuando grandes empresarios y tecnócratas aparecen en la escena asesorando, junto con diferentes personalidades de derecha, en la confección del plan de gobierno del Frente Democrático (FREDEMO), ${ }^{13}$ con un sentido neoliberal radical de los cambios que se debían llevar a cabo (Vargas Llosa 1993). Su presencia, sin embargo, está subordinada a las personalidades y empresarios amigos de Vargas Llosa,

12 La tesis central de De Soto es que los pobres tienen recursos que no están valorizados en el mercado. Si, por ejemplo, les dieran títulos de propiedad por su pequeño lote de terreno urbano, podrían transarlo en el mercado y obtendrían un capital para trabajar. Se olvida De Soto que el capitalismo no es una utopía de pequeños propietarios en competencia permanente, sino una realidad de acumulación que marcha al monopolio y a la liquidación de la pequeña propiedad.

13 El FREDEMO fue un frente político para las elecciones de 1990 entre el movimiento Libertad de Vargas Llosa, el Partido Popular Cristiano, Acción Popular y el grupo de tecnócratas Solidaridad y Democracia (SODE). 
ligados a la clase alta y media alta de Lima, que se esfuerzan por dejar su marca, colonial y racista, en la campaña en curso. El ingreso a posiciones de gobierno recién se da con el ajuste económico de agosto de 1990, para afincarse en el poder luego del golpe Estado del 5 de abril de 1992.

Es importante señalar que, con el triunfo electoral de Fujimori y el posterior golpe de Estado, los líderes de los partidos tradicionales - Acción Popular, PPC y SODE - y buena parte de las personalidades que acompañaron a Vargas Llosa, incluyendo al propio escritor, se alejan del gobierno elegido. Esto sucede porque están en desacuerdo con el carácter autoritario de sus acciones. Lo mismo no pasa con los grandes empresarios y los tecnócratas que más bien señalan que Fujimori, especialmente en términos económicos, está cumpliendo con su programa.

La derecha neoliberal, ya sin Fujimori y Montesinos, continúa en democracia. Es preciso, sin embargo, señalar de qué democracia se trata. He dicho en otros textos calificando la precariedad de la democracia peruana (Lynch 2009, 2014), que esta es una democracia sin democratización. Esto significa que los dos elementos de desarrollo democrático, la sociedad civil y los partidos políticos, se encuentran trabados en su desarrollo. La primera por la brutal fragmentación a la que ha sido sometida por el modelo neoliberal que ha dañado el mercado interno, la empresa nacional y el trabajo con derechos, haciendo muy difícil el desarrollo del tejido social y la expresión colectiva. Pero, al mismo tiempo, porque se han dado una importante cantidad de leyes que criminalizan la protesta social hasta hacerla casi imposible. Por otra parte, los partidos políticos, fuertemente golpeados ya por la violencia terrorista y el ajuste económico, ven muy difícil su labor proselitista y gravemente disminuida su capacidad de representar políticamente. Se ha llegado incluso en el momento de auge del neoliberalismo, de satanizar la actividad política, especialmente por parte de los grandes empresarios, que la han caracterizado como "ruido político" que perjudica la actividad económica, por lo que este debe ser considerado indeseable. A esta situación se agrega el control ideológico de los medios de comunicación, para diferenciarlo del control político directo durante la época de Fujimori y Montesinos, cuyos dueños se compran el modelo económico y político neoliberal en su integridad y en las versiones más extremas que profesan los grandes propietarios y sus aliados extranjeros. Es cierto que la falencia de los partidos ayuda en este sentido, pero la misma es promovida por los medios, que prefieren la proliferación de etiquetas que tener rivales en la confección de la agenda pública. Es risible, en este senti- 
do, la tan mentada "libertad de expresión" que dicen profesar empresarios, tecnócratas y políticos en este tiempo. Esta situación ha hecho del electorado peruano un conjunto volátil, que difícilmente establece lealtad política con organización alguna y suele moverse de acuerdo con las ofertas de la coyuntura. A diferencia de lo que han planteado otros (Tanaka 2005, Vergara 2012), la peruana no es solo una democracia sin partidos, hecho de por si grave, sino una democracia sin democratización, es decir sin los motores para desarrollarse, situación más grave aún.

Los gobiernos de Valentín Paniagua (2000-2001), Alejandro Toledo (2001-2006), Alan García (2006-2011), Ollanta Humala (2011-2016), Pedro Pablo Kuczynski (2016- 2018) y Martín Vizcarra (2018-2021) profundizan la captura en democracia. Paniagua ${ }^{14}$ es el único que expresa algún reparo ante esta captura, pero sin tomar ninguna acción importante. En algún momento se pensó que podía cambiar o, aunque fuera reformar la Constitución de 1993, pero la oposición de derecha y la falta de tiempo conspiró contra ello. Las claves de esta continuidad en democracia han sido dos: la mantención de la Constitución írrita de 1993 y la continuación con el modelo económico. Lo que se traduce en la captura del Estado y el capitalismo de amigotes antes señalado, con la diferencia frente al período anterior que hay un personal permanente, que son los tecnócratas neoliberales y un personal eventual, curiosamente los que se supone que mandan, que son los políticos elegidos. De igual manera, los líderes y las personalidades en general son muchos más importantes que los partidos políticos. Sean estos partidos con trayectoria o movimientos de ocasión, sirven nada más como maquinarias electorales y eventuales canales de clientelismo, que se desactivan o languidecen entre una elección y otra. Por lo demás, como señala Durand (2019), la captura del Estado supone la compra de los políticos, financiando sus campañas electorales y sobornando a los que deciden sobre los contratos de obra pública, como hemos visto hasta la saciedad en estos años en el Perú; pero también imponiendo equipos que diseñan políticas que se heredan entre un gobierno y otro. Sobre esta base es que se desarrolla la relación de los grandes empresarios y los tecnócratas en los siguientes gobiernos. Como antes, aquí también hay diferencias, a principios del siglo XXI la relación con los grandes empresarios

14 Valentín Paniagua fue un personaje del momento anterior de la política peruana, que sucede como señalamos entre 1962 y 1990. Militó primero en la Democracia Cristiana y luego en Acción Popular. Si bien asumió las posiciones conservadoras a las que evolucionó este segundo partido, estaba marcado por el afán reformista del período que intentó separar a los propietarios del Estado y establecer este como una esfera relativamente autónoma. 
fue difícil porque estaban frescas las denuncias de corrupción contra ellos. Sin embargo, cuando se asienta Alejando Toledo en la presidencia el panorama se compone para grandes empresarios y tecnócratas. Repasando los distintos gobiernos democráticos, tenemos lo siguiente:

Alejandro Toledo es un político que aparece en escena en el momento de crisis del fujimorismo, señalando que iba a construir "el segundo piso" de las reformas neoliberales que había comenzado Fujimori, enorgulleciéndose de su calidad de independiente y en los términos de la época ajeno a los partidos anteriores a 1990. Toledo se radicaliza por el fraude en contra suyo que realizan Fujimori y Montesinos en las elecciones del año 2000 y se niega a presentarse a la segunda vuelta electoral. En esta coyuntura es que se encuentra con el movimiento antidictatorial y se convierte en el líder de este, lo que lo lleva a ganar las elecciones libres del 2001. Forma un primer gabinete apoyándose en el movimiento antidictatorial, pero rápidamente se aísla del electorado que lo lleva al triunfo y tiene serios choques con los movimientos sociales. $\mathrm{Su}$ capacidad de gobierno fue reducida y en su cuarto año en el poder, con $8 \%$ de aprobación durante 13 meses seguidos, casi es vacado si no fuera por los poderes fácticos de la economía y la seguridad que lo sostuvieron.

Alan García fue un político de gran recorrido, militante de un partido tradicional de la política peruana como es el Partido Aprista y con una primera experiencia de gobierno entre 1985 y 1990, que fue considerada como desastrosa (Reyna 2000). Sin embargo, en el 2006 se presenta transformado, con críticas menores al modelo neoliberal y mostrando su experiencia como la llave para un buen gobierno. Se caracterizó en el poder por su represión al movimiento social y la implementación del Tratado de Libre Comercio con Estados Unidos. De los cinco presidentes posteriores a Paniagua y haciendo gala de su calidad de converso fue el que más cercanía tuvo con grandes empresarios y tecnócratas. De igual manera, buscó cultivar las mejores relaciones con los Estados Unidos tomando la iniciativa en la formación de la Alianza del Pacífico, coalición de países de tendencia neoliberal que buscaba contrarrestar la Unión de Naciones Sudamericanas.

Ollanta Humala, por su parte, es el caso de conversión más súbdita y radical. Fue elegido en el 2011 con una plataforma nacionalista de izquierda y en el curso del primer año viró a la derecha neoliberal. Curiosamente, el nacionalismo de izquierda era una prédica que mantenía desde el año 2001, cuando como oficial del Ejército peruano lideró un levantamiento en la localidad de Locumba contra Fujimori, en las postrimerías del gobierno autoritario. 
Postuló el 2006 con su plataforma radical y quedó segundo, continuando con su prédica por el país hasta ser elegido en los siguientes comicios. Antes de jurar como presidente ya entregó varios ministerios claves a los neoliberales, ente ellos el de Economía y Finanzas y luego, progresivamente, la mayor parte del gobierno. Al final su lema de campaña "la gran transformación", terminaría en el desván de los recuerdos.

Pedro Pablo Kuczynski, por su parte, une su calidad de gran empresario a la de tecnócrata y más precisamente technopol desde sus inicios en la década de 1960, para ser elegido presidente el 2016. En su caso no podemos hablar de que fungía de otra cosa que no fuera de neoliberal, ni que su gobierno no tuviera ese sello. Sin embargo, llegó a la presidencia porque logró el apoyo, para la segunda vuelta, del sector antifujimorista del electorado, principalmente de izquierda, consiguiendo así la victoria. Se rodeó desde un primer momento de un grupo de tecnócratas muy similares a él, con aspiraciones de technopols, lo que profundizó la visión externa, casi extranjera que tenía del país, que lo llevaría finalmente a su debacle. Por último, Martín Vizcarra no es un presidente elegido como tal, sino que como vicepresidente de Kuczynski lo sucede, luego de las graves acusaciones de corrupción contra este, en marzo del 2018. Más allá de su lucha contra el resurgimiento fujimorista, ha demostrado ser leal al neoliberalismo y mantener la captura tecnocrática y las relaciones de privilegio con la gran empresa.

El gran ausente en esta revisión de los actores de la continuidad en democracia parece ser el fujimorismo, pero lo presento así porque es el único que no ha vuelto al gobierno y sin embargo todos los demás continuistas se ven interpelados, para bien o para mal, por él. En una primera etapa, hasta mediados del segundo gobierno de Alan García, parece ser un recuerdo más de la política peruana, su candidata del 2006 , una líder histórica de su movimiento Martha Chávez, apenas logra el $8 \%$ de la votación. Sin embargo, de allí en adelante, bajo el liderazgo de Keiko Fujimori cambia el panorama, logrando el segundo lugar, ajustadamente, el 2011, frente a un candidato claramente opuesto como es Humala y mejorando su perfomance el 2016, cuando queda nuevamente a muy poco de ganar la presidencia frente a Kuczynski. Hasta el 2006, el fujimorismo repite las formas y contenidos de los noventas, pero con Keiko Fujimori de líder las cosas cambian, buscando sofisticar su aparato clientelista y aparecer como una mejor continuidad en democracia que sus rivales de derecha. Asimismo, no llega a la autocrítica abierta como movimiento de los "errores" autoritarios del pasado, pero señala que estos ya no 
podrían repetirse en las actuales condiciones. El nuevo rostro, sin embargo, se desbarata por la actuación obstruccionista que tiene su mayoría parlamentaria frente al gobierno de Kuczynski y su sucesor Vizcarra, así como los casos de corrupción en que se ve envuelta la propia Keiko Fujimori y varios de sus colaboradores, regresando, luego de la disolución de la Asamblea Legislativa en la que era mayoría, a una situación subordinada y de pronóstico reservado en la escena peruana.

Pero lo interesante es que la propuesta neoliberal nunca se presenta directamente en democracia hasta la candidatura de Kuczynski. Toledo es el "cholo sano y sagrado" que debería reivindicar a las mayorías de ancestro indígena en el Perú. García provenía de un partido popular, como originalmente había sido el Partido Aprista y su prédica, si bien más explícita en términos neoliberales que la de Toledo, recién se terminaría de aclarar en el ejercicio del gobierno. Humala simple y llanamente cambió de programa y de aliados en poco tiempo, siendo hasta hoy un misterio el origen de su traición y dando esto posibilidades para los peores pensamientos. Kuczynski es el que, más allá de sus simpatías o antipatías personales, nunca ocultó programa, pero necesitó el endoso de su contraria para poder ganar. En otras palabras, ha habido un manejo de la demanda electoral exitoso, aunque distorsionador, por la derecha neoliberal que debemos desentrañar.

En todos los casos, sin embargo, se mantiene un elenco estable de tecnócratas de la derecha neoliberal, que desarrollan la ocupación, como ya señalé, del Ministerio de Economía y Finanzas, extendiéndose con las sucesivas administraciones a los demás ministerios y reparticiones del Estado que consideran importantes para avanzar sus intereses. Se trata de las mismas personas o de sus protegidos, provenientes de los mismos colegios y universidades privadas que van y vuelven de acuerdo con las circunstancias. Hasta ahora, en el período neoliberal, no ha importado el presidente o el ministro de turno, igual pugnan y la mayor parte de las veces lo logran, por continuar con las políticas centradas en el mercado y la meritocracia neoliberal. De igual manera, en la mayor parte de los casos, provienen de la clase media alta o alta de ancestro europeo. Una minoría étnica y social que como en los tiempos coloniales se ha dado maña para permanecer, apoyada por los grandes poderes del empresariado nacional e internacional a los que sirve.

La estabilidad del grupo tecnocrático y su importancia para el régimen político en su conjunto ha sido resaltada por Eduardo Dargent (2014) y Francisco Durand (2019). Sin embargo, Dargent resalta la contribución de los 
tecnócratas, quizás todavía desde la ilusión de un momento de auge, para la continuidad del modelo neoliberal, mientras que Durand hace hincapié en su lugar en una estructura de poder. Esto último me parece central, en un régimen político en el que los grandes propietarios vigilan, los tecnócratas administran y los políticos actúan tomando decisiones cada vez en un marco más estrecho.

La gran pregunta es por qué se ha mantenido esta continuidad. Alberto Vergara (2012) señala que por el éxito del modelo económico. Quizás esta fue la razón de la simpatía inicial con el fujimorismo de la mayoría de la población, porque en ese momento el ajuste y la estabilización permitieron salir de la pesadilla de la hiperinflación. Sin embargo, con el paso de los años "el éxito del modelo" se ha convertido en el mantra que repiten la abrumadora mayoría de políticos, empresarios, comentaristas de opinión y por supuesto los tecnócratas, que se rasgan las vestiduras si alguien osa contradecirlos. Opino lo contrario que Vergara, a contracorriente del orden establecido neoliberal, señalo que el modelo para la mayoría de los peruanos ha sido un fracaso. Si bien en treinta años el producto bruto interno (PBI) se ha multiplicado por tres, esta riqueza como señalamos al principio está muy mal repartida. Agregando al indice de Gini que ya referimos, tenemos la distancia de 20 a 1 entre los deciles primero y último de la escala de ingresos (Alarco, Castillo y Leiva 2019), a lo que podemos agregar que, en uno de los años exitosos del modelo, me refiero al 2012, en cuanto a producción de riqueza, solo el $12 \%$ de la población económicamente activa (PEA) tenía un trabajo con derechos (Gamero 2013). Todo esto con la pandemia de COVID-19, se ha agravado muchísimo. No hay, por ello, un éxito del modelo.

¿Qué sucede entonces? Hay un problema de oposición política y también de hegemonía ideológica.

En cuanto a la oposición a la derecha neoliberal en democracia, creo que solo ha existido oposición como alternativa en las elecciones del 2006, 2011 y 2016. En los dos primeros casos se trató de la candidatura de Ollanta Humala, que quedó segundo el 2006 y ganó el 2011; en el 2016 de la candidatura de Verónika Mendoza que quedó tercera con casi $20 \%$ de la votación y apoyó, por menos malo, a Kuczynski contra Keiko Fujimori en la segunda vuelta. Sin embargo, si bien en todos los casos sacó mayores votaciones la candidatura de Humala, su carácter caudillista y personalista y la evolución posterior, nos hace ver que una candidatura más claramente independiente y alternativa, por el liderazgo desarrollado, el programa presentado y su conducta política, ha sido la de Verónika Mendoza. El problema es que recién hemos tenido una 
candidatura claramente alternativa un cuarto de siglo después de establecida la hegemonía neoliberal. Creo que, desde los predios opositores, especialmente los izquierdistas, que han sido siempre el núcleo de la oposición a la derecha neoliberal, ha habido un camino muy difícil por recorrer y no siempre sus protagonistas han sido plenamente conscientes de estas dificultades. La triple crisis de fines de la década de 1980, con el fracaso del primer gobierno aprista de Alan García que termina en una hiperinflación desenfrenada, la derrota del terrorismo senderista por la vía de la guerra sucia por parte de las Fuerzas Armadas y policiales, y la división de la Izquierda Unida, ${ }^{15}$ producen una hecatombe en las fuerzas de izquierda que enfrentan, diezmadas ya, la década de 1990. El ajuste, el golpe y la nueva Constitución que establece la derecha neoliberal proceden sin oposición real por estas razones. Esto hace de la izquierda una fuerza política subordinada hasta el año 2016. Los fragmentos de la explosión de fines de los ochenta hacen política a la sombra de otros, caudillos más o menos democráticos y/o nacionalistas, hasta el 2016. Recién este año se presenta una alternativa que tiene además la novedad del recambio generacional. Ya no son las mismas caras de la derrota y la resistencia, ahora aparece una nueva generación portadora de nuevas sensibilidades, que no sin dificultades junta las reivindicaciones de la antigua izquierda de la justicia social y la soberanía nacional con los derechos de los pueblos originarios, el medio ambiente y la igualdad de género.

En cuanto a la hegemonía ideológica, efectivamente hay contenidos transmitidos por los poderes político, económico y mediático desde la década de 1990, que subrayan la importancia de la iniciativa individual y la competencia en el mercado, y que permanecen en el sentido común de la población. Asimismo, el elogio a la informalidad ha tomado la forma del emprendedor, que sería la persona sin recursos que se atreve a enfrentar los obstáculos de una burocracia insensible para poder tener un negocio propio con el cual hacer dinero. Este mensaje continúa poniendo de lado los sentidos de justicia, nación y derechos sociales, marginando de cualquier espacio a los individuos u organizaciones que osen plantearlos. Con lo cual tiene a la defensiva cualquier pensamiento sobre estos temas. Sin embargo, acepta el debate sobre la igualdad de género y la destrucción del medio ambiente como cuestiones de la

15 La Izquierda Unida fue en la década de 1980 un frente partidos de izquierda muy exitoso para la época, logrando ganar la alcaldía de Lima en 1983 y quedando segundo en las elecciones presidenciales de 1985. Lo destruyó la división interna y su incapacidad para señalar una alternativa a la crisis de fines de esa década. 
globalización a las cuales debemos prestar atención. Esto último ha permitido la alianza tácita, y a veces no tanto, entre sectores progresistas y un sector de la tecnocracia neoliberal que ve en estas sensibilidades temas de época y como tales insoslayables. Sin embargo, esta coincidencia está lejos de abordar las relaciones de estos mismos temas con el capitalismo salvaje que los promueve.

La permanencia de estos contenidos ideológicos neoliberales en la población, y la carencia de caminos eficaces para enfrentarlos, quizás sea la mayor dificultad para plantear una alternativa al neoliberalismo en estos tiempos.

\section{La derecha neoliberal frente a la crisis}

El Perú atraviesa en la actualidad una crisis de régimen que no presenta solución a la vista. En otras palabras, el arreglo institucional que establece el neoliberalismo para llevar adelante sus políticas en la década de 1990 y sus ajustes posteriores ya no funcionan más. El escenario de todos los expresidentes encausados por corrupción, un Parlamento que es visto por la población como una institución inservible y un Poder Judicial en reorganización casi permanente, más allá de las excepciones de algunos parlamentarios, jueces y fiscales probos, hacen que la política y el aparato del Estado sean vistos con gran desconfianza por la población (Latinobarómetro 2018). La gran diferencia hoy frente a años y décadas anteriores es que la corrupción ha empezado a ser menos tolerada por los ciudadanos. El dicho popular "roba, pero hace obra", que mostraba un cinismo ciudadano frente a la posibilidad de cambiar algo, parece ya no ser tan fuerte y los escándalos, ciertamente con más espacios de contestación política parecen importarle más a la gente que en la época de la dictadura fujimorista. La corrupción de esta manera empieza a ser asociada, sobre todo en medio de la pandemia del COVID-19, con la pobreza de los servicios públicos, la falta de un Estado que vele por el interés general y, más todavía, las posibilidades de futuro como país.

El telón de fondo de esta crisis está en la economía, la baja de la demanda de materias primas, minerales en el caso peruano, por parte del mercado mundial, especialmente por China. Esta demanda mantuvo un alto crecimiento del PBI que en los años de auge llegó al $8 \%$ anual, mientras que en el año anterior a la pandemia ha rondado el $2 \%$ y se cree que con la crisis del coronavirus caeremos en una recesión que podría llegar al -14 \% del PBI (INEI 2019). 
Esta crisis de régimen, que se ha agudizado con la crisis de la pandemia, ha tenido hasta ahora su escenario más importante en una crisis en las alturas. Los escándalos de corrupción que han remecido al país en los últimos cuatro años tienen a todos los ex presidentes de la república de la era neoliberal, salvo Valentín Paniagua, enjuiciados o presos por delitos relacionados a financiación de campañas políticas y/o sobornos para la concesión de obras públicas e influencia indebida. Todos los gobiernos neoliberales, salvo el de transición de principios del siglo XX, están manchados.

Esta situación de descrédito de la clase política neoliberal ha tenido su corolario en los últimos cuatro años en las graves dificultades para gobernar el país. Primero, por la propia dificultad para gobernar en medio del escándalo de las denuncias, investigaciones y juicios; pero también por los graves enfrentamientos entre los poderes ejecutivo y legislativo que han dejado al Perú sin un norte claro por dónde avanzar. Este enfrentamiento ha tenido como protagonistas, en un primer momento, a la mayoría fujimorista del Congreso de la República que aliada al Partido Aprista trató de bloquear el gobierno de Kuczynski primero y Vizcarra después, para acortar su mandato y que su lideresa Keiko Fujimori tuviera una vía más rápida a la Presidencia de la República. Esto parecía concretarse cuando las serias denuncias por corrupción obligaron a Kuczynski a renunciar a la presidencia en marzo del 2018, siendo sucedido por su vicepresidente Martín Vizcarra, quien para sorpresa de muchos ha buscado tomar la iniciativa con un proyecto de reforma política y judicial. El proyecto de reforma de Vizcarra dio algunos pasos, pero finalmente se entrampó y en el curso del enfrentamiento con el Congreso disolvió la Asamblea Legislativa y convocó a elecciones extraordinarias para completar el período de esta. Estas nuevas elecciones han dado como resultado un Congreso más fragmentado y sin una orientación clara hacia delante, en el que predominan los intereses personales y de grupo de muy corto plazo, por lo que el pronóstico de la situación es reservado.

En estas condiciones, desde la sociedad civil y la oposición democrática, no se han desarrollado opciones consistentes de salida para la situación política. En el período 2018-2019, de enfrentamiento entre los poderes ejecutivo y legislativo, se desarrollaron frecuentes movilizaciones ciudadanas contra el control del fujimorismo y el Partido Aprista del Congreso de la República y la oposición obstruccionista que realizaban al gobierno de Vizcarra, aunque las mismas no alcanzaron una masividad que las convirtiera en un factor de crisis por si solas. Además, tampoco han tenido una expresión política clara que las 
sustentara ni una proyección en las elecciones legislativas complementarias. La alternativa de Verónika Mendoza y su movimiento Nuevo Perú empieza a destacar, pero no se ha establecido como un competidor definitivo. Asoman también alternativas radicales que podrían cosechar de la crisis de régimen si encuentran el espacio para ello.

Esto nos deja con un conflicto que se da entre dos facciones de la derecha neoliberal y principalmente en las alturas. Por una parte, tenemos al fujimorismo venido a menos por su actuación política en los últimos años y nuevamente identificado, aunque las caras fueran otras, con el actuar mafioso de la década de 1990. Investigaciones recientes de Francisco Durand y Emilio Salcedo (2019) sobre el financiamiento no declarado de la campaña de 2011 que encabezara Keiko Fujimori demuestran que más de la mitad de los aportes no fueron hechos públicos, respondieron a la gran empresa y no fueron gastados en la campaña electoral. Esto, según informa el diario La República (2020) ha sido recogido por el Ministerio Público, que desarrolla la hipótesis de que el partido Fuerza Popular, que lidera Keiko Fujimori, se ha convertido en una organización criminal al servicio de sus financistas y de sus líderes.

Asimismo, el Partido Aprista, otrora el gran partido nacional popular de la política peruana, ha devenido en una fuerza neoliberal menor y de futuro incierto. Sin embargo, el golpe de la pandemia a la estructura de poder y el descrédito de sus antiguos representantes ha hecho resurgir a los propios grandes propietarios como actores públicos, ya sea directamente o a través de su gremio, la Confederación Nacional de Instituciones Empresariales Privadas (CONFIEP), hoy especialmente locuaz ante la agudización de la crisis. Por otra, a los tecnócratas que han buscado convertirse en technopols, que tuvieron su mejor expresión en Kuczynski y luego han tratado de acomodarse con Vizcarra. Estos, que creíamos ya hundidos en el negocio de los intereses mayores de los propietarios, levantan cabeza con un gobierno como el de Francisco Sagasti, que sin reparar en su carácter provisorio enarbola de nuevo la bandera de la técnica. Los primeros insisten en el neoliberalismo, que se tramita por la vía del negocio oscuro y la prepotencia pública. Los segundos, le prestan más atención a la etiqueta e insisten en que controlan las bondades de un saber que les permite "hacer las cosas bien". Su opción es apelar a la opinión pública para obtener el apoyo del que carecen por no contar con bases organizadas y encontrar un nuevo rostro que les permita continuar controlando los principales resortes del poder tras bambalinas. Ninguno de los dos logra articular un proyecto para el país que no sea la repetición de lo ante- 
rior, aunque los tecnócratas insisten en la posibilidad de remozar la propuesta económica y entroncarla con la, hoy congelada, reforma política. ¿Será eso posible? No tenemos certezas al respecto.

Hasta antes de la crisis de régimen, a mediados del 2018, hubiera dicho que los tecnócratas harían el tránsito, que contradictoriamente resisten y al mismo tiempo anhelan, de convertirse en technopols, "salvar los muebles"16 del neoliberalismo e intentar una reconstrucción. Pero hoy, ante la incertidumbre existente por la pandemia planetaria, creo que todas las opciones, para continuar el camino de esta derecha, la dictadura incluida, permanecen abiertos.

En estas condiciones, ¿qué le queda a la derecha peruana? Los sectores más ligados a los grandes propietarios, que expresan con más nitidez su energía de clase, insisten en vender su proyecto oligárquico como el único posible para el conjunto del país, manifestando la urgencia de volver al momento anterior de auge neoliberal para salir de los estragos actuales. De esta forma el espíritu encomendero, al que hacíamos alusión al principio del texto, se mantiene firme insistiendo en la vieja tesis de que un pequeño grupo puede continuar viviendo a costa de los demás. El problema es que el velo ideológico que sostenía esta ilusión en la era neoliberal se ha caído. La idea de que cualquiera puede progresar si se esfuerza ha vuelto a demostrarse falsa. Peor todavía, la dialéctica amo-esclavo propia de la antigua dominación oligárquica, donde el esclavo está convencido de la bondad de su condición, a casi doscientos años de república y luego de diversos momentos democratizadores, se vuelve a demostrar también falsa.

El régimen político, por último, que esta derecha neoliberal nos ha traído, primero como dictadura, en su versión maquillada de "autoritarismo competitivo" y luego como democracia, en la experiencia limitada y parcial, me hace ver la contradicción entre esta versión del capitalismo y la posibilidad de brindar efectivamente a los ciudadanos la posibilidad de decidir sobre su destino.

Esta propuesta, virulenta en la actualidad, de vuelta al neoliberalismo original, no repara en el deterioro sufrido por la falta de legitimidad de su dominación que quizás haga imposible una renovación hegemónica en los mismos términos. Así las cosas, la continuidad de unos en el poder solo estará garantizada por la debilidad de los otros, en oposición al manejo oligárquico, para desplazarlos.

16 Salvar los muebles, que refiere en su origen a salvar los muebles de una casa en un incendio, es una expresión que se usa para señalar que alguien quiere salvar lo mejor de una experiencia terminada. 


\section{Referencias bibliográficas}

Adrianzén, C. A. 2014. Una obra para varios elencos. Nueva Sociedad, 254.

Alarco, G., Castillo, C. y Leiva, F. 2019. Riqueza y desigualdad en el Perú. Visión panorámica. Lima: OXFAM.

Araníbar, C. 1979. El principio de la dominación (1531-1580). Nueva historia general del Perú. Lima: Mosca Azul Editores.

Bobbio, N. 1996. Left and Right. The Significance of a Political Distinction. Chicago: The University of Chicago Press,

Comisión de la Verdad y Reconciliación. 2004. Informe final (t. I.). Lima: CVR.

Cotler, J. 1978. Clases, Estado y nación en el Perú. Lima: IEP

Cotler, J. 2000. La gobernabilidad en el Perú. Entre el autoritarismo y la democracia $E l$ fujimorismo. Ascenso y caída de un régimen autoritario. Lima: IEP.

Chávez Molina, J. 2000. Mis votos singulares. Historia de un fraude que no debe repetirse. Lima: Editorial Horizonte.

Dargent, E. 2014. Technocracy and democracy in Latin America: the experts running government. New York: Cambridge University Press.

De Soto, H. 1989. El otro sendero. Lima: Instituto Libertad y Democracia.

Dammert, M. 2001. El Estado mafioso. El poder imagocrático en las sociedades globalizadas. Lima: Ediciones El Virrey.

Domínguez, J. I. 1998. Ideas and Leaders in Freeing Politics and Markets in Latin America in the 1990s. Democratic Politics in Latin America and the Caribbean. Baltimore, Londres: The Johns Hopkins University Press.

Durand, F. 2010. La mano invisible del mercado. Crítica a los neoliberales criollos. Lima: Fondo Editorial del Pedagógico de San Marcos.

Durand, F. 2019. La captura del Estado en América Latina. Reflexiones teóricas. Lima: OXFAM, Fondo Editorial de la PUCP.

Durand, F. y E. Salcedo, 2019. La democracia del dinero. Otra Mirada, jueves 12 de mayo.

Franco, C. 1985. Los significados de la experiencia velasquista: forma política y contenido social. El Perú de Velasco (t. II). Lima: Centro de Estudios para el Desarrollo y la Participación.

Gamero, J. 2007. The Shock Doctrine. The rise of disaster capitalism. New York: Metropolitan Books.

Gamero, J. 2013. El trabajo decente en el Perú. Una mirada al 2012. Lima: IESI. INEI.

Gamero, J. 2019. Panorama de la economía peruana 1950-2018. Lima: INEI. 
Latinobarómetro. 2018. Informe 2018. Santiago de Chile: Corporación Latinobarómetro. www.latinobarómetro.org.

López, S. 1991. El Estado oligárquico en el Perú, un ensayo de interpretación. El Dios mortal. Estado, sociedad y política en el Perú del siglo XX. Lima: Instituto Democracia y Socialismo.

Lynch, N. 1999. Neopopulismo: un concepto vacío. Socialismo y Participación, 86.

Lynch, N. 2002. Los usos de los medios en el Perú de Fujimori. En Peruzzotti, E. y Smulovitz, C. (Eds.). Controlando la política. Ciudadanos y medios en las nuevas democracias latinoamericanas. Buenos Aires: Temas Grupo Editorial.

Lynch, N. 2009. El argumento democrático sobre América Latina. La excepcionalidad peruana en perspectiva comparada. Lima: Universidad Nacional Mayor de San Marcos. Fondo Editorial de la Facultad de Ciencias Sociales.

Lynch, N. 2014. Cholificación, república y democracia. Lima: Otra Mirada.

Marini, R. M. 1973. Dialéctica de la dependencia. Ciudad de México: Ediciones Era.

Meléndez, C. 2019. La derecha que se bifurca. Las vertientes populistas, conservadora y democrático liberal en Perú post 2000. Colombia Internacional, 99, 3-27.

Pease, H. 1977. El ocaso del poder oligárquico. Lima: DESCO.

Pease, H. 2003. La autocracia fujimorista: del Estado intervencionista al Estado mafioso. Lima: Fondo Editorial de la PUCP.

Quijano, A. 2000. Colonialidad del poder, eurocentrismo y América Latina. En Lander, E. (Comp.). La colonialidad del saber: eurocentrismo y ciencias sociales. Perspectivas latinoamericanas. Buenos Aires: CLACSO.

Quiroz, A. 2013. Historia de la corrupción en el Perú. Lima: IEP, IDL.

Reyna, C. 2000. La anunciación de Fujimori. Alan García 1985-1990. Lima: DESCO.

Roberts, K.1995. Neoliberalism and the Transformation of populism in Latin America. The Peruvian Case. World Politics, 48.

Romero, César. 2020. Keiko Fujimori, una candidata bajo sospecha judicial. La República, miércoles 16 de diciembre.

Rospigliosi, F. 2000. El arte del engaño. Las relaciones entre los militares y la prensa. Lima: edición del autor.

Schady, N. 1999. Seeking Votes. The Political Economy of Expenditures by Peruvian Social Fund (Foncodes) 1991-1995. Washington D. C: Banco Mundial.

Sartori, G. 1970. Concept Misformation in Comparative Politics. The American Political Science Review, 64 (4).

Tanaka, M. 2005. Democracia sin partidos: Perú, 2000-2005. Los problemas de representación y las propuestas de reforma política. Lima: IEP.

Thurner, M. 2006. Republicanos andinos. Lima: Centro Bartolomé de las Casas, IEP. 
Vargas Llosa, M. 1993. El pez en el agua. Barcelona: Editorial Seix Barral S. A.

Vergara, A. 2012. Alternancia sin alternativa: ¿un año de Humala o veinte años de un sistema? Argumentos. Revista de análisis y crítica, 3.

Watchel, N. 1976. Los vencidos. Los indios del Perú frente a la conquista española (15301570). Madrid: Alianza Editorial.

Weber, M. 1982. La política como vocación. Escritos políticos II. Ciudad de México: Folios Ediciones S. A.

Weyland, K. 1997. Neopopulismo y neoliberalismo en América Latina: afinidades inesperadas. Pretextos, 10. 